\title{
Ensino de Matemática através da Resolução de Problemas: alguns aspectos orientadores para a prática docente
}

Teaching mathematics through problem solving: some teaching practice guidelines

\author{
Bruno Rodrigo Teixeira ${ }^{1}$ \\ Edilaine Regina dos Santos ${ }^{2}$
}

\section{Resumo}

Neste artigo, a partir de uma revisão de literatura, destacamos aspectos que podem ser orientadores para a prática do professor no ensino de Matemática através da Resolução de Problemas. Para isso, apresentamos considerações a respeito do planejamento da tarefa matemática e das ações do professor na condução de uma aula nessa concepção de ensino. Com relação ao planejamento da tarefa, a literatura tem evidenciado que a escolha dela deve levar em conta fundamentalmente a matemática que o professor gostaria que seus alunos aprendessem, e, que a antecipação de possíveis resoluções pode auxiliar na condução do discurso com a turma. No que tange à condução da aula, a literatura tem apresentado sugestões tanto no que se refere a que ações o professor pode desenvolver durante o trabalho com os alunos quanto no que diz respeito a como pode desenvolvê-las. Dada a complexidade do ensino de Matemática através da Resolução de Problemas, consideramos que tais sugestões podem auxiliar professores no desenvolvimento de uma prática baseada nessa concepção de ensino.

Palavras-chave: Educação Matemática. Ensino de Matemática. Resolução de Problemas.

\section{Introdução}

Segundo Lester (2013, p. 259, tradução nossa) "diferentes perspectivas sobre o que a aprendizagem Matemática envolve terão uma enorme influência sobre o que os professores devem ser capazes de fazer em suas salas de aula." Diante disso, para discutir a respeito de aspectos orientadores da prática docente,

1 Doutor em Ensino de Ciências e Educação Matemática. Docente do Departamento de Matemática da Universidade Estadual de Londrina (UEL). E-mail: bruno@uel.br

2 Doutora em Ensino de Ciências e Educação Matemática. Docente do Departamento de Matemática da Universidade Estadual de Londrina (UEL). E-mail: edilaine.santos@uel.br 
que assume determinada concepção de ensino, é importante explicitar qual perspectiva de aprendizagem está atrelada a ela.

Em relação às concepções de ensino de Matemática baseadas em Resolução de Problemas, Prado e Allevato (2010, p. 26-27, grifo das autoras) destacam, ao considerar a história da Resolução de Problemas, que

[...] encontramos denominações diferenciadas por preposições que caracterizam três tipos de concepções de ensino baseadas em Resolução de Problemas: ensinar sobre Resolução de Problemas, ensinar para a Resolução de Problemas e ensinar através da Resolução de Problemas. $O$ principal representante da concepção de ensino de Matemática sobre a Resolução de Problemas é George Polya (1994) [...]. Segundo Polya (1994), a resolução de um problema exige quatro etapas: a compreensão da tarefa; a concepção de um plano que leve à meta pretendida; a execução desse plano; a análise para determinar se a meta foi atingida. [...] Na concepção de ensinar para a Resolução de Problemas, os professores costumam utilizar os problemas para apresentarem aplicações dos conteúdos matemáticos. Primeiramente, apresentam uma parte teórica dos conteúdos matemáticos, e depois, propõem problemas sobre aquele conteúdo. [...] essa é a forma como a grande maioria dos professores realiza seu ensino nas aulas de Matemática. [...] a concepção do Ensino de Matemática através da Resolução de Problemas, [...] se trata de um trabalho em que um problema é ponto de partida e orientação para a aprendizagem, e a construção do conhecimento se faz através de sua resolução.

Assim, no ensino de Matemática através da Resolução de Problemas - em que a resolução de problemas é concebida como "o meio através do qual conceitos, processos e procedimentos matemáticos são aprendidos" (LESTER, 2013, p. 246, tradução nossa) -,

[...] a aprendizagem ocorre durante o processo de tentar resolver problemas nos quais conceitos e habilidades matemáticas relevantes estão embutidos. À medida que os alunos resolvem problemas, eles podem usar qualquer abordagem em que possam pensar, se basear em qualquer conhecimento que aprenderam e justificar suas ideias de maneira que consideram convincentes. Esse ambiente de aprendizagem fornece um cenário natural para os alunos apresentarem várias soluções para o seu grupo ou classe e aprender matemática através de interações sociais, negociando significado e chegando a um entendimento compartilhado. Tais atividades ajudam os alunos a esclarecer suas ideias e adquirir diferentes perspectivas do conceito ou ideia que eles estão aprendendo. (CAl, 2010, p. 10, tradução nossa).

Nesse sentido, Selmer e Kale (2013, p.50, tradução nossa) também destacam que no ensino de Matemática através da Resolução de Problemas, 
resoluções apresentadas pelos alunos e aprendizagem de conceitos matemáticos são interdependentes: "a aprendizagem matemática é dependente de os alunos resolverem o problema e a resolução do problema é o canal para os alunos se envolverem com a matemática."

Tendo em vista a perspectiva de aprendizagem assumida no ensino através da Resolução de Problemas, discorremos a seguir, pautados em uma revisão de literatura, acerca de alguns aspectos que podem ser orientadores para a prática docente no desenvolvimento das ações em uma aula baseada nessa concepção de ensino, tendo como foco o planejamento da tarefa ${ }^{3}$ matemática a ser utilizada e a condução do trabalho com essa tarefa em sala de aula, com destaque para a organização da discussão com toda a turma visando à sistematização de ideias e à formalização de conceitos, princípios e procedimentos matemáticos.

\section{Sobre o planejamento da tarefa matemática}

Segundo Van de Walle (2009, p. 68), um "elemento-chave para o ensino com resolução de problemas é a seleção de problemas ou tarefas apropriados" 4 . Para o autor, um problema é definido como "qualquer tarefa ou atividade na qual os estudantes não tenham nenhum método ou regra já receitados ou memorizados e nem haja uma percepção por parte dos estudantes de que haja um método 'correto' específico de solução" (VAN DE WALLE, 2009, p. 57). Desse modo, para que uma tarefa se constitua em um problema, "o professor não pode prescrever aos estudantes os métodos e/ou regras específicas para que obtenham a solução." (ALLEVATO; ONUCHIC, 2014, p. 44).

\footnotetext{
${ }^{3}$ Uma tarefa pode ser definida "como um segmento da atividade de sala de aula que é dedicada ao desenvolvimento de uma determinada ideia matemática. Uma tarefa pode envolver vários problemas relacionados ou trabalho prolongado, [...] em um único problema complexo." (STEIN, SMITH, 1998, p. 269, tradução nossa)

${ }^{4}$ Segundo o autor, essas tarefas podem ser adaptadas, por exemplo, de livros didáticos, de artigos publicados em revistas de Educação Matemática. Nesse sentido, sugerimos que podem ser adaptadas também de provas como as do PISA, da OBMEP, de vestibulares.
} 
Ainda para esse autor (VAN DE WALLE, 2009, p. 58):

Ao resolver o problema ou fazer a atividade, os alunos devem estar preocupados principalmente em dar significado à matemática envolvida e, assim, desenvolver sua compreensão sobre essas ideias. Embora seja aceitável e até mesmo desejável ter contextos para os problemas que os tornem interessantes, esses aspectos não devem ser o foco da atividade.

Muitas vezes, segundo Selmer e Kale (2013, p. 50, tradução nossa), os professores

[..] enfatizam a importância de fornecer problemas matemáticos do mundo real para os alunos, mas mais importante para o ensino de Matemática através da Resolução de Problemas é que uma tarefa focalize a atenção dos alunos sobre os conceitos matemáticos que fazem parte dela.

Assim, na escolha da tarefa matemática "os professores precisam, primeiramente, considerar a matemática que eles gostariam que seus alunos aprendessem" (SELMER; KALE, 2013, p. 50, tradução nossa). Para isso, o professor "precisa preparar, ou escolher, problemas apropriados ao conteúdo ou ao conceito que pretende construir." (ONUCHIC; ALLEVATO, 2011, p. 82).

Outro aspecto que pode ser levado em conta na seleção do problema pelo professor é que "pesquisadores recomendam que os estudantes devam ser expostos a tarefas verdadeiramente problemáticas e desafiadoras para que eles tenham oportunidades de se engajarem na produção de sentido matemático" (CAI, 2010, p.12, tradução nossa). Com relação ao aspecto problemático da tarefa, Van de Walle (2009, p. 68) aponta que "deve ser a matemática na tarefa que a torna problemática para os estudantes de modo que as ideias matemáticas sejam as suas preocupações básicas."

Ainda em relação ao planejamento da tarefa, após a seleção do problema, o professor pode trabalhar na antecipação de possíveis resoluções dos alunos. Larsson e Ryve (2011), baseando-se em Stein et al. (2008), enfatizam que essa ação de antecipar pode auxiliar o professor durante a aula na condução do discurso com a turma.

Sobre o que a ação de antecipar as respostas dos alunos envolve e o que requer do professor, Stein et al. (2008) discorrem: 
Antecipar as respostas dos alunos envolve o desenvolvimento de expectativas consideradas sobre como os alunos podem interpretar matematicamente um problema, a coleção de estratégias - tanto corretas quanto incorretas - que eles podem usar para lidar com a tarefa, e como essas estratégias e interpretações podem se relacionar com conceitos, representações, procedimentos e práticas matemáticas que o professor gostaria que seus alunos aprendessem. [...]

A antecipação exige que os professores, no mínimo, realmente façam as tarefas matemáticas que eles estão planejando pedir para seus alunos fazerem. No entanto, em vez de encontrar uma única estratégia para resolver um problema, os professores precisam criar e trabalhar com tantas estratégias diferentes de resolução quanto puderem. Além disso, se eles se colocam na posição de seus alunos ao fazerem a tarefa, eles podem antecipar algumas das estratégias que os alunos com diferentes graus de sofisticação matemática são capazes de produzir e considerar maneiras que os estudantes podem interpretar mal os problemas ou ficarem confusos ao longo do caminho [...]. Cada vez que eles usam uma tarefa, os professores podem aumentar seu conhecimento sobre as respostas prováveis dos alunos. (STEIN et al., 2008, p. 322-323, tradução nossa).

Assim, ao realizar a ação de antecipar as respostas dos alunos para um problema no planejamento de uma aula para ensinar Matemática através da Resolução de Problemas, tendo em vista a organização das discussões com toda a turma, é importante o professor, entre outros aspectos ${ }^{5}$ : resolver o problema utilizando diferentes estratégias; prever possíveis resoluções dos alunos (elaboradas a partir de estratégias e interpretações corretas ou incorretas). Além disso, prever dúvidas ou dificuldades que eles podem apresentar ao longo do trabalho de resolução, intervenções para auxiliá-los; e, destacar como alguma resolução pode oportunizar a formalização de conceitos ou procedimentos matemáticos, afinal, a matemática que o professor gostaria que seus alunos aprendessem é o aspecto central a ser levado em conta na seleção do problema. Nesse sentido, assim como destacam Stein, Boaler e Silver (2003) a respeito dos desafios que surgem quando se usa uma abordagem de ensino de forma eficaz, tem-se "a necessidade de os professores desenvolverem uma compreensão sólida e flexível do terreno matemático que seus alunos irão atravessar". (STEIN; BOALER; SILVER, 2003, p. 256).

${ }^{5}$ Exemplos de tarefas planejadas para ensinar Matemática através da Resolução de Problemas, contendo elementos como esses destacados, podem ser obtidos em Onuchic et al. (2014); Souza, Foglie e Santos (2015); Benedito, Fornazier e Teixeira (2016). 
Considerando que a antecipação de respostas dos alunos para um problema pode auxiliar o professor na condução do discurso com a turma, essa ação se torna de extrema importância no planejamento da aula, tendo em vista que no ensino de Matemática através da Resolução de Problemas a organização do discurso em sala de aula pelo professor consiste em um aspecto fundamental para promover a compreensão e a aprendizagem matemática dos alunos (SELMER; KALE, 2013; CAI, 2003, 2010; VAN DE WALLE, 2009).

De modo geral, no planejamento de uma aula nessa concepção de ensino "o professor seleciona ou elabora um problema e propõe aos alunos [...]. Esse problema inicial é chamado problema gerador, pois visa à construção de um novo conteúdo, conceito, princípio ou procedimento" (ALLEVATO; ONUCHIC, 2014, p. 45). Sobre o planejamento que o professor pode fazer em torno desse problema foi o que discorremos até o presente momento. Contudo, gostaríamos de destacar que além desse problema inicial o professor pode também selecionar ou elaborar outros relacionados a ele para propor aos alunos durante o trabalho em sala de aula. Esses outros problemas

[...] possibilitam analisar se foram compreendidos os elementos essenciais do conteúdo matemático introduzido naquela aula e consolidar as aprendizagens construídas [...], bem como aprofundar e ampliar as compreensões acerca daquele conteúdo ou tópico matemático, gerando um círculo que se configura pela construção de novos conhecimentos e pela resolução de novos problemas, e assim por diante. Essa etapa teria forte viés do ensino para a resolução de problemas, contudo, isso não desconfigura a metodologia porque essa concepção (através) inclui as demais (sobre e para) [...] (ALLEVATO; ONUCHIC, 2014, p. 46).

\section{Sobre a condução da aula}

Para o início do trabalho em sala de aula é importante que o professor primeiramente explicite aos alunos a dinâmica da aula (SOUZA; FOGLIE; SANTOS, 2015), a fim de que eles tenham clareza a respeito de como será realizado, o modo que serão organizados para esse trabalho, o que se espera 
deles, o que podem esperar do professor, e, como e em que momento o conteúdo matemático será abordado.

Em seguida, o professor apresenta aos alunos, seja por meio de registro na lousa, seja impresso, o enunciado do problema gerador. Após isso, segundo Allevato e Onuchic (2014, p. 45), solicita aos alunos que façam a sua leitura individualmente, tendo "possibilidade de refletir, de colocar-se em contato com a linguagem matemática e desenvolver sua própria compreensão do problema proposto". Realizada essa leitura, o professor então pede aos alunos que se reúnam em pequenos grupos e façam nova leitura e discussão do enunciado do problema (ALLEVATO; ONUCHIC, 2014).

Além de Allevato e Onuchic (2014), Lester (2013) também destaca a organização dos alunos em pequenos grupos para o trabalho nessa perspectiva. Para o autor, entre os princípios importantes que emergiram a partir da investigação a respeito da Resolução de Problemas desde o início da década de 1970, está “o princípio da interação do grupo" (LESTER, 2013, p. 273, tradução nossa) em que:

[...] A organização padrão para atividades de ensino em sala de aula é os alunos trabalharem em pequenos grupos (normalmente grupos de três ou quatro). O trabalho em pequenos grupos é especialmente adequado para atividades envolvendo novos conteúdos (por exemplo, novos tópicos de matemática, novas estratégias de resolução de problemas) ou quando o foco da atividade está no processo de resolução de problemas (por exemplo, planejamento, tomada de decisão, avaliação de progressos), ou explorar ideias matemáticas. (LESTER, 2013, p. 273, tradução nossa).

Contudo, segundo Van de Walle (2009, p. 62), "quando trabalham em grupos, sempre há a possibilidade de alguns não contribuírem ou de um aluno dominador conduzir os demais." Nesse sentido, o autor apresenta como opção uma abordagem "por etapas em que eles primeiro trabalham sozinhos (refletem) e depois conversam e trocam ideias com um parceiro." (VAN DE WALLE, 2009, p. 62, grifo do autor). Para ele:

Independentemente de os alunos estarem ou não trabalhando em grupos, sempre é uma boa ideia que eles tenham alguma oportunidade para discutir suas ideias com um ou mais colegas antes de compartilharem seus 
pensamentos [...] [com toda a turma]. Quando trabalham sozinhos, os estudantes não têm ninguém para conversar sobre alguma ideia ou sobre algum modo de começar se estiverem bloqueados. (VAN DE WALLE, 2009, p. 62).

Em relação a como pode ser feita a organização dos alunos nos grupos, esse autor assinala que

É muito mais proveitoso apostar na diversidade em sua sala de aula usando duplas ou grupos cooperativos que sejam heterogêneos. Alguns professores gostam de usar grupos fortuitos ou permitir que os estudantes escolham aqueles com os quais querem trabalhar. Essas técnicas podem ser ocasionalmente divertidas, mas é aconselhável refletir sobre como você vai agrupar seus alunos. Tente agrupar os que têm dificuldades com os mais capazes, mas que também sejam compatíveis e estejam dispostos a colaborar. O que todos os estudantes vão descobrir é que todos têm ideias para contribuir. (VAN DE WALLE, 2009, p. 86).

Com os alunos já organizados em grupos e com a leitura do problema finalizada, o professor precisa verificar se o enunciado foi compreendido pelos alunos. Segundo Van de Walle (2009, p. 62), "essa ação não é opcional! Você sempre deve estar seguro de que os alunos compreenderam o problema antes de deixá-los trabalhar."

Para isso, o autor sugere que o professor se atente, por exemplo, para o caso de o vocabulário ter sido mal compreendido ${ }^{6}$. Além disso, indica que também "é útil verificar se os alunos podem explicar o que o problema está perguntando. [...] fazer os estudantes recontarem o problema em suas próprias palavras lhes obriga a pensar exatamente sobre o que o problema está perguntando." (VAN DE WALLE, 2009, p. 62).

Estando seguro de que os alunos compreenderam o enunciado do problema, o professor então solicita que desenvolvam sua resolução (ALLEVATO; ONUCHIC, 2014). Enquanto eles resolvem o problema, é importante que o

\footnotetext{
${ }^{6}$ Nesse sentido, Onuchic e Allevato $(2011$, p. 83 ) apontam que, caso haja "no texto do problema, palavras desconhecidas para os alunos, surge um problema secundário. Busca-se uma forma de poder esclarecer as dúvidas e, se necessário, pode-se, com os alunos, consultar um dicionário."
} 
professor gerencie o tempo ${ }^{7}$, acompanhe o trabalho dos alunos e realize ações como as seguintes:

[...] Escute ativamente os seus estudantes. Ocupe esse tempo em descobrir como os diferentes alunos estão pensando, que ideias estão usando e como estão abordando o problema. Esse é um momento para observação e avaliação - e não para transmissão ou informação!

[...] Cuidadosamente, ofereça sugestões adequadas - mas apenas sugestões baseadas nas ideias dos estudantes e nos seus modos de pensamento. Tenha muito cuidado para não sugerir que você detém o método correto de resolver o problema.

[...] Forneça atividades adequadas aos alunos que terminarem mais rápido. (VAN DE WALLE, 2009, p. 64).

$\mathrm{Na}$ realização dessas ações pelo professor, Van de Walle (2009, p. 65-66)

ainda destaca, entre outros, os seguintes aspectos a serem considerados:

[...] Escutar ativamente inclui fazer perguntas, como as seguintes, e mostrar um interesse pelas ideias dos estudantes.

- O que você acha que o problema está perguntando?

- Que ideias você já tentou até agora?

- Você tem alguma ideia sobre qual deve ser a resposta? Por que você pensa assim?

Fazendo perguntas desse tipo você descobre onde os alunos estão e mostra que você valoriza suas hipóteses. [...] Quando os pensamentos de um estudante mostram alguma promessa, indiferentemente de quão vagos ou primitivos, você pode dizer, "Por que você não trabalha nessa abordagem? Eu acho que ela pode lhe levar a algum lugar".

$[\ldots]$

Se um grupo ou aluno está procurando um lugar por onde começar, uma sugestão pode ser apropriada. Você pode sugerir que eles tentem usar um modelo interativo particular, desenhar uma figura ou fazer uma tabela se uma dessas ideias parecer apropriada ${ }^{8}$.

[...] a escolha de uma sugestão é realizada melhor após ouvir cuidadosamente o que o estudante tem tentado fazer ou pensado. Depois de oferecer uma sugestão, caia fora. Não fique rondando ou o aluno vai ficar esperando por mais orientação sem fazer qualquer esforço pessoal.

[...] Os alunos olharão para você pedindo aprovação para seus resultados ou ideias. Evite ser a fonte da "verdade" ou do estar "certo ou errado". Quando

7 Segundo Van de Walle (2009) o professor precisa ter o cuidado para que esta etapa de resolução não se estenda muito de modo que não haja tempo suficiente para a discussão. Para o início da discussão "não é necessário que todos os alunos tenham terminado." (p. 66)

${ }^{8} \mathrm{O}$ autor exemplifica como isso pode ser feito a partir de um problema em Van de Walle (2009, p. $65)$.

9 "Quando você observa um erro ou pensamento incorreto, não o corrija imediatamente. Os alunos têm de aprender desde o início que os seus erros podem ser úteis [...]. As melhores discussões acontecem quando há discordâncias. Se você corrigir todo pensamento incorreto, você terá menos debates, reduzirá a segurança dos alunos em seu próprio pensamento e terá menos ideias para uma discussão rica e proveitosa." (VAN DE WALLE, 2009, p. 65) 
Ihe perguntarem se um resultado ou método está correto, responda dizendo, "Como você pode decidir?" ou "Por que você pensa que isso estaria certo?" ou "Eu entendi o que você fez. Como você pode conferir isso?". Até mesmo se não lhe pedirem uma opinião, pergunte "Como nós podemos dizer se isso faz sentido?". Lembre os alunos que respostas sem explicações não são aceitáveis. [...]

Alguns alunos sempre terminarão bem antes do que os outros. Estes estudantes precisam ser envolvidos com eficiência, de modo que não se tornem fonte de problemas, sem que pareça aos outros que seja uma recompensa de uma atividade divertida por terem terminado depressa. Os que completam as atividades mais rápido geralmente podem ser desafiados de alguma maneira conectada ao problema recém resolvido. [...]

Muitos problemas bons são superficialmente simples. As extensões que são desafiadoras. [...] Questões que começam com: "E se você tentar...?" ou "A mesma ideia vai funcionar para...?" também são modos de sugerir diferentes extensões ${ }^{10}$.

Ainda com relação às ações do professor nesse momento da aula, em que os alunos trabalham na resolução do problema, Allevato e Onuchic (2014, p.4546) apontam que ele pode agir "incentivando-os a utilizar seus conhecimentos prévios e técnicas operatórias já conhecidas, e incentivando a troca de ideias." Esse compartilhamento de ideias entre os alunos pode ser oportunizado estrategicamente pelo professor a fim de explorar diferentes estratégias entre eles, pedir para justificarem suas respostas, e fazer perguntas para sondar os entendimentos que têm a respeito de determinados conceitos (SELMER; KALE, 2013). Incentivar os alunos a justificarem suas respostas vai ao encontro de uma necessidade destacada por Van de Walle (2009, p. 63) no ensino através da Resolução de Problemas: "[...] que os alunos mudem o foco de sua atenção do obter apenas as respostas para os processos e argumentos de como eles obtiveram as respostas". Segundo o autor, isso pode ajudá-los inclusive a se prepararem para a discussão com toda a turma.

Além disso, Allevato e Onuchic (2014) e Selmer e Kale (2013) enfatizam, assim como Van de Walle (2009), que auxiliar os alunos que necessitem de ajuda durante a resolução do problema sem fornecer respostas prontas a eles, também é uma ação que pode ser desenvolvida pelo professor.

${ }^{10} \mathrm{O}$ autor sugere, inclusive, que estas "extensões para os que completarem as tarefas primeiro" sejam previstas no planejamento da aula. (VAN DE WALLE, 2009, p. 84) 
Ao ensinar matemática através da Resolução de Problemas "um dos dilemas mais desconcertantes é o quanto dizer aos alunos. Por um lado, dizer reduz a reflexão deles. [...] Por outro lado, dizer muito pouco algumas vezes pode resultar em tropeços e desperdiçar um tempo precioso das aulas." (VAN DE WALLE, 2009, p. 75).

Para auxiliar o professor em relação a como lidar com esse dilema, Van de Walle (2009, p. 75), baseado no trabalho de outros pesquisadores, salienta que os professores "devem se sentir livres para compartilhar informação pertinente, contanto que a matemática na tarefa permaneça desafiadora (problemática) para os alunos" e apresenta três tipos de informação que os professores podem fornecer aos alunos:

Convenções matemáticas. As convenções sociais de simbolismo e de terminologia (nomenclatura) importantes em matemática nunca serão desenvolvidas por pensamento reflexivo. Por exemplo, representar "três e cinco dá oito" como " $3+5=8$ " é uma convenção. Definições e nomenclaturas também são convenções. O importante é oferecer esses símbolos e palavras apenas quando os alunos precisarem deles ou os acharem úteis. Como uma regra geral, o simbolismo e a terminologia só devem ser introduzidos depois de os conceitos serem desenvolvidos, como um meio de expressar ou nomear ideias. Eles raramente devem ser apresentados de início ou como coisas a serem memorizadas.

Métodos alternativos. Você pode, com cuidado, sugerir aos alunos um método ou uma abordagem alternativa para reflexão. [...]

Esclarecimento dos métodos dos alunos. Você deve ajudá-los a esclarecer ou interpretar as suas ideias e talvez relacioná-las com outras. [...] A discussão ou esclarecimento das ideias dos alunos concentra a atenção sobre as ideias que você quer que a turma aprenda. [...]. (VAN DE WALLE, 2009, p. 75-76, grifo do autor)

Tendo em vista que nessa concepção de ensino é típico primeiramente o professor deixar os estudantes trabalharem em uma resolução e, em seguida, utilizar essas resoluções como sustentação para uma discussão em sala de aula (SELMER; KALE, 2013), enquanto acompanha o trabalho dos alunos ele precisa se atentar para "a utilização de diversas soluções [...] para maximizar as oportunidades de aprendizagem matemática para os alunos através do discurso de sala de aula." (SELMER; KALE, 2013, p. 51, tradução nossa). 
No ensino através da Resolução de Problemas, a condução do discurso matemático é uma atividade altamente complexa para os professores (CAI, 2003). Com a intenção de apoiá-los nesse desafio, Larsson e Ryve (2011) discutem a respeito de algumas ações que podem auxiliar em relação a isso.

A partir de resoluções previstas por um professor para um problema e selecionadas enquanto monitorava ${ }^{11} \mathrm{o}$ trabalho dos alunos, os autores abordam um modelo de cinco práticas proposto por Stein et al. (2008), para orquestrar discussões matemáticas produtivas com toda a turma, que

[...] enfatiza aspectos que podem ser planejados com antecedência para orquestrar discussões matemáticas. [...] As cinco práticas são: antecipar as respostas dos alunos, monitorar as respostas dos alunos durante a fase de exploração, selecionar as respostas dos alunos para a discussão com toda a turma, sequenciar as respostas dos alunos e conectar as respostas dos alunos entre si e com ideias matemáticas poderosas. A prática de fazer conexões baseia-se em e se beneficia das práticas que a precedem. (LARSSON; RYVE, 2011, p.425-426, grifo nosso, tradução nossa).

Larsson e Ryve (2011, p. 429, tradução nossa) apresentam sugestões para selecionar, sequenciar e conectar as resoluções para um problema "a fim de criar o máximo de oportunidades para conectar as soluções dos alunos e, assim, facilitar discussões matemáticas eficazes que tanto se baseiam em suas ideias quanto desenvolvem ideias matemáticas importantes", algo fundamental no ensino através da Resolução de Problemas, em que as resoluções servem como suporte para as discussões e ponto de partida para a sistematização de ideias e a formalização de conceitos e procedimentos matemáticos.

Com relação a aspectos que o professor pode se atentar tendo em vista as práticas de selecionar e sequenciar as resoluções dos alunos, Stein et al. (2008) destacam, por exemplo:

Tendo monitorado as respostas dos alunos disponíveis na turma, o professor pode então selecionar determinados alunos para compartilhar seu trabalho com o resto da classe [...]. Uma maneira típica de fazer isso é convidar alunos específicos (ou grupos de alunos) para apresentar o seu trabalho à medida

\footnotetext{
${ }^{11}$ Segundo Stein et al. (2008, p. 326, tradução nossa) "o objetivo do monitoramento é identificar o potencial de aprendizagem matemática de estratégias ou representações particulares usadas pelos alunos, se atentando para quais respostas dos alunos seriam importantes para compartilhar com toda a turma durante a fase de discussão."
} 
que a discussão prossegue. Alternativamente, um professor pode pedir voluntários, mas depois selecionar um estudante em particular que ele sabe que é um dos vários que tem uma ideia particularmente útil para compartilhar com a classe. (p. 327-328, tradução nossa).

Tendo selecionado determinados alunos para apresentar, o professor pode então tomar decisões sobre como sequenciar as apresentações dos alunos [...]. Ao fazer escolhas intencionais sobre a ordem em que o trabalho dos alunos é compartilhado, os professores podem maximizar as chances de que seus objetivos matemáticos para a discussão sejam alcançados. Por exemplo, o professor pode querer que a estratégia usada pela maioria dos alunos seja apresentada antes daquelas que apenas alguns estudantes usaram, para ajudar a validar o trabalho que os alunos fizeram e tornar 0 início da discussão acessível a tantos alunos quanto possível [...] Outra possibilidade de sequenciamento é começar com uma estratégia comum que se baseia em uma ideia equivocada que vários alunos tiveram para que a classe possa esclarecer esse mal-entendido [...]. Além disso, o professor pode querer que estratégias relacionadas ou contrastantes sejam apresentadas umas após as outras para tornar mais fácil para a turma compará-las matematicamente [...]. Assim, ao invés de estar à mercê de quando os alunos passam a contribuir com uma ideia para uma discussão, os professores podem selecionar os alunos para apresentar em uma determinada sequência para fazer uma discussão mais coerente e previsível matematicamente. (p. 329-330, tradução nossa)

Além desses aspectos referentes às ações do professor, tendo em vista a preparação das discussões que serão realizadas com toda a turma, os estudantes "devem compreender que quando Ihes for atribuído uma determinada tarefa que uma de suas responsabilidades é se preparar para a discussão que acontecerá depois de trabalhar no problema" (VAN DE WALLE, 2009, p. 74). Para ilustrar esse fato, Van de Walle (2009) apresenta o exemplo de uma professora que, para ajudar seus alunos a tornarem-se mais responsáveis, elaborou cartazes com as seguintes questões: "Como você resolveu o problema? Por que você resolveu o problema desse modo? Por que você acredita que sua solução está correta e faz sentido?' (p. 74, grifo do autor).

Após o trabalho dos alunos na resolução do problema, o professor então explicita aos alunos a seleção e o sequenciamento das resoluções que serão compartilhadas tendo em vista o início de uma discussão com toda a turma. Allevato e Onuchic (2014) sugerem que sejam convidados representantes dos grupos para fazerem o registro das resoluções na lousa. Segundo as autoras “diante desse 'painel de soluções' [certas, erradas ou feitas por diferentes 
processos], o professor estimula os alunos a compartilhar e justificar suas ideias, defender pontos de vista, comparar e discutir as diferentes soluções" (ALLEVATO; ONUCHIC, 2014, p.46). Cabe ressaltar que resoluções iguais não precisam ter seus registros repetidos na lousa. (ALLEVATO; ONUCHIC, 2009).

Assim como Allevato e Onuchic (2014), Van de Walle (2009) também apresenta, a partir de diversas pesquisas, sugestões de ações a serem desenvolvidas nessa etapa de discussão com a turma:

- Encoraje o diálogo entre alunos em vez de conversações entre alunos e professor que excluam a turma. "Joana, você pode responder a pergunta da Laura?", "Denis, você pode explicar isso de forma que Tadeu e José possam compreender o que você está dizendo?". [...]

- Exija explicações para acompanhar todas as respostas. Assim, o pedido para uma explicação não sinalizará que uma resposta esteja incorreta, como as crianças inicialmente acreditarão. [...] Exigindo explicações, os alunos aprendem que o raciocínio em matemática é importante e útil.

- Convoque os alunos para apresentar suas ideias e chame, primeiro, as crianças que tendem a ser tímidas ou ainda não tenham a habilidade de se expressar muito bem. Quando são chamadas a participar desde cedo e recebem um tempo suficiente para formularem os seus raciocínios, estas crianças reservadas podem participar mais facilmente e assim serem valorizadas. [...]

- Encoraje os estudantes a fazerem perguntas. "Pedro, você compreendeu como eles fizeram isso? Alguém quer fazer uma pergunta para o Antônio?"

- Certifique-se de que seus alunos também compreenderam o que você compreende. Seu conhecimento sobre o tópico pode lhe fazer aceitar uma explicação menos clara porque você acaba ouvindo o que o aluno pretendia dizer (e não conseguiu de fato dizer). Selecione pontos importantes na explicação de um estudante e expresse sua própria "confusão". "Carlos, eu não entendi bem por que você subtraiu 9 aqui neste passo. Você pode nos dizer por que fez isso?" Demonstre aos alunos que é normal ficar confuso e que perguntar questões de esclarecimento é apropriado. Uma meta é que os alunos façam essas perguntas sem que você precise dispará-las.

- Ocasionalmente pergunte àqueles que compreenderam que apresentem explicações aos outros. "Tânia, talvez você possa explicar essa ideia com suas palavras de modo que alguns de nós possamos compreender melhor". Não pressuponha que um aluno que disse que compreendeu tenha realmente compreendido.

- Aproxime os alunos de explicações mais baseadas em conceitos sempre que for apropriado. Por exemplo, se um aluno diz que sabe que 4,17 é maior do que 4,1638 você pode lhe pedir (ou a um outro) para explicar por que isso é assim. [...] Da mesma forma, não deixe os alunos apenas listarem os passos de suas resoluções. "Eu vejo o que você fez, mas acho que alguns ainda não entenderam por que você fez isso desse modo e por que você pensa que isso nos dará a solução correta". (VAN DE WALLE, 2009, p. 67) 
$\mathrm{Na}$ discussão das resoluções dos alunos com toda a turma, conforme já mencionado anteriormente, é importante que o professor também busque estabelecer conexões entre as resoluções dos alunos. Sobre a prática de conectar as respostas dos alunos, Stein et al. (2008) apontam que o objetivo é que as apresentações sejam relacionadas para desenvolver poderosas ideias matemáticas e que para isso existem diferentes maneiras de os professores ajudarem a turma a estabelecer conexões:

$\mathrm{Na}$ transição entre as apresentações de dois alunos, um professor pode referir-se a algumas das maneiras pelas quais as estratégias e as ideias matemáticas dos dois alunos podem ser semelhantes ou diferentes entre si nos tipos de representações, operações e conceitos utilizados [...]. Ou os professores podem pedir aos alunos que identifiquem o que é semelhante ou diferente nas duas apresentações. (STEIN et al., 2008, p. 331, tradução nossa).

Nesse sentido, Larsson e Ryve (2011), por exemplo, não propõem meras conexões entre fórmulas algébricas para um determinado padrão observado na resolução de um problema, "mas conexões entre diferentes formas de representações - numéricas, algébricas e gráficas" (p. 431, tradução nossa), embora destaquem que conectar fórmulas algébricas para um padrão também seja algo produtivo para as discussões matemáticas. Os autores consideram ainda que "é produtivo discutir explicitamente vantagens e desvantagens de diferentes soluções" (p. 430, tradução nossa).

Após a discussão com os alunos e considerando a matemática que o professor gostaria que eles aprendessem, tida em mente desde o momento de seleção do problema, ele

[...] registra na lousa uma apresentação "formal" - organizada e estruturada em linguagem matemática - padronizando os conceitos, os princípios e os procedimentos construídos através da resolução do problema, destacando diferentes técnicas operatórias e construindo demonstrações, se for o caso. (ALLEVATO; ONUCHIC, 2014, p. 46).

Para isso, podem ser utilizadas as seguintes orientações propostas por Van de Walle (2009, p. 68). 
Quando você estiver satisfeito com a discussão sobre a resposta e a resolução para o problema, resuma os pontos principais da discussão e verifique se todos os alunos compreenderam. Tente usar a terminologia usada pelos estudantes. Quando as ideias forem bem-desenvolvidas, introduza os termos, as definições ou o simbolismo apropriados. As "etiquetas" (nomenclaturas) vêm após o estabelecimento das ideias, e não antes.

Caso em meio às resoluções apresentadas pelos alunos não haja alguma que o professor considera como sendo propícia para a formalização do conteúdo, ele pode sugerir outra forma de resolução e desenvolvê-la com a participação deles, de modo a desencadear a formalização pretendida.

Em Allevato e Onuchic (2009, p.12), por exemplo, ao constatar que os participantes de um minicurso não haviam tentado trabalhar com a busca por padrões a partir de um problema, "a pesquisadora encaminhou as atividades comentando com os participantes que, juntos, o problema seria resolvido utilizando uma estratégia que eles ainda não haviam abordado". A partir das diferentes resoluções obtidas para o problema em questão e outros problemas relacionados a ele foi evidenciado "como é possível que novos conceitos e novos conteúdos sejam apresentados aos alunos a partir e através de problemas" ( $p$. 14).

Tendo realizado a formalização do conteúdo matemático, que segundo Onuchic e Allevato (2011, p. 82) "passa a fazer mais sentido para os alunos", o professor pode solicitar que façam o registro escrito dessas informações e, em seguida, propor outros problemas relacionados ao problema gerador que estejam previstos em seu planejamento (para os quais em sua resolução já poderão inclusive recorrer a esses registros escritos), com a intenção de, conforme já destacado anteriormente, "analisar se foram compreendidos os elementos essenciais do conteúdo matemático introduzido naquela aula e consolidar as aprendizagens construídas [...] bem como aprofundar e ampliar as compreensões acerca daquele conteúdo ou tópico matemático" (ALLEVATO; ONUCHIC, 2014, p. 46). 


\section{Considerações}

Diante da complexidade do ensino de Matemática através da Resolução de Problemas, neste artigo buscamos destacar aspectos que podem ser orientadores para uma prática docente baseada nessa concepção de ensino. Nesse sentido, cabe destacar que nossa intenção é que esse trabalho possa auxiliar o professor no desenvolvimento de práticas em aspectos que evidenciamos como centrais a partir da literatura revisada.

De modo geral, foi possível evidenciar com relação ao planejamento da tarefa, que ela deve ser selecionada com base na matemática que o professor gostaria que seus alunos aprendessem (VAN DE WALLE, 2009; ONUCHIC; ALLEVATO, 2011; SELMER; KALE, 2013); e, que a antecipação de possíveis resoluções pode auxiliar na condução do discurso com a turma (LARSSON; RYVE, 2011).

Segundo Lester (2013), tendo em vista que o planejamento dos professores tem recebido pouca atenção como um fator de importância na pesquisa sobre o ensino através da Resolução de Problemas, pesquisas futuras deveriam considerar como os professores planejam suas aulas para trabalhar nessa perspectiva e como as decisões tomadas durante 0 planejamento influenciam as ações durante o ensino. Levando em conta esses apontamentos do autor, aspectos como os que destacamos a partir da presente revisão de literatura podem motivar a realização de pesquisas com foco mais específico no planejamento do professor e sua influência nas ações em sala de aula, na aprendizagem dos alunos, e até mesmo em seu desenvolvimento profissional.

No que tange à condução da aula foi possível apresentar sugestões tanto referentes à que ações o professor pode desenvolver quanto no que diz respeito a como pode desenvolvê-las.

Sobre as ações a serem desenvolvidas durante o trabalho com os alunos, salientamos: 
- explicitar aos alunos a dinâmica da aula (SOUZA; FOGLIE; SANTOS, 2015);

- apresentar, por escrito, o enunciado do problema (ALLEVATO; ONUCHIC, 2014);

- solicitar aos alunos que façam a leitura do enunciado (ALLEVATO; ONUCHIC, 2014);

- organizá-los em pequenos grupos (LESTER, 2013; ALLEVATO; ONUCHIC 2014), ou realizar uma abordagem por etapas (VAN DE WALLE, 2009);

- verificar se o enunciado foi compreendido e realizar intervenções caso não tenha sido (VAN DE WALLE, 2009; ONUCHIC; ALLEVATO, 2011);

- solicitar que desenvolvam sua resolução (ALLEVATO; ONUCHIC, 2014), acompanhar esse trabalho dos alunos (VAN DE WALLE, 2009; ALLEVATO; ONUCHIC, 2014) e gerenciar o tempo (VAN DE WALLE, 2009);

- selecionar, sequenciar e conectar as resoluções dos alunos (LARSSON; RYVE, 2011);

- propor a discussão de resoluções com toda a turma (VAN DE WALLE, 2009; SELMER; KALE, 2013; ALLEVATO; ONUCHIC, 2014);

- sistematizar ideias (VAN DE WALLE, 2009) e formalizar conceitos, princípios e procedimentos matemáticos a partir de resoluções discutidas (VAN DE WALLE, 2009; ALLEVATO; ONUCHIC, 2014).

A respeito de como o professor pode desenvolvê-las, destacamos sugestões em aspectos referentes:

- à organização dos alunos nos grupos (VAN DE WALLE, 2009);

- à realização de intervenções caso o enunciado do problema não tenha sido compreendido (VAN DE WALLE, 2009; ONUCHIC; ALLEVATO, 2011); 
- ao acompanhamento do trabalho dos alunos durante a resolução do problema (VAN DE WALLE, 2009; ALLEVATO; ONUCHIC, 2014);

- à seleção e ao sequenciamento das resoluções a serem apresentadas para toda a turma, assim como ao estabelecimento de conexões entre essas resoluções (STEIN et al., 2008; LARSSON; RYVE, 2011);

- à preparação dos alunos para a discussão com toda a turma (VAN DE WALLE, 2009);

- à dinamização dessa discussão (VAN DE WALLE, 2009; ALLEVATO; ONUCHIC, 2014);

- à sistematização de ideias (VAN DE WALLE, 2009) e formalização de conceitos, princípios e procedimentos matemáticos a partir de resoluções discutidas (VAN DE WALLE, 2009; ALLEVATO; ONUCHIC, 2009, 2014).

Gostaríamos de assinalar que ensinar Matemática através da Resolução de Problemas requer de professores e alunos "mudanças de atitude e postura, o que, nem sempre, é fácil conseguir." (ONUCHIC; ALLEVATO, 2011, p. 82). Contudo, professores "que ensinam dessa maneira se empolgam e não querem voltar a ensinar na forma dita tradicional. Sentem-se gratificados com a constatação de que os alunos desenvolvem a compreensão por seus próprios raciocínios." (ONUCHIC; ALLEVATO, 2011, p. 82, grifo das autoras).

Para finalizar, vale destacar que o professor precisa estar ciente de que, conforme destacam Cai (2010) e Lester (2013), é necessário tempo para que os estudantes se familiarizem com esse tipo de trabalho, e, com isso, possa torná-lo parte integrante de seu programa da disciplina.

\section{Referências}

ALLEVATO, N. S. G.; ONUCHIC, L. R. Ensinando Matemática na sala de aula através da Resolução de Problemas. Boletim GEPEM, Rio de Janeiro, ano 33, n. 55, p. 1- 19, jul./dez. 2009. 
ALLEVATO, N. S. G; ONUCHIC, L. R. Ensino-Aprendizagem-Avaliação de Matemática: por que Através da Resolução de Problemas? In: ONUCHIC, L. R. et al. (Orgs.).

Resolução de Problemas: Teoria e Prática. Jundiaí: Paco Editorial, 2014, p. 35-52.

BENEDITO, J. E. G.; FORNAZIER, V. S.; TEIXEIRA, B. R. Potencialidades formativas da prática de antecipar no âmbito do Estágio Curricular Supervisionado em Matemática. In: Encontro Nacional de Educação Matemática, 12, 2016, São Paulo. Anais... São Paulo: Universidade Cruzeiro do Sul, 2016. p. 1-12.

CAI, J. What research tells us about Teaching Mathematics through Problem Solving. In: LESTER, F. K. Jr; (Ed.). Teaching Mathematics through Problem Solving:

Prekindergarten-Grade 6. Reston, VA: NCTM, 2003, p. 241-254.

CAI, J. Helping Elementary School Students Become Successful Mathematical Problem Solvers. In: LAMBDIN, D. V. (Ed.). Teaching and learning mathematics: translating research for elementary school teachers. Reston, VA: NCTM, 2010, p 9-14.

LARSSON, M.; RYVE, A. Effective teaching through problem-solving by sequencing and connecting student solutions. In: GUNNARSDÓTTIR, G. H. et al. (Eds.). Proceedings of NORMA11: The sixth Nordic conference on mathematics education in Reykjavik, Reykjavik: University of Iceland Press, 2011, p. 425-434.

LESTER, F. K. Jr. Thoughts About Research On Mathematical Problem - Solving Instruction.The Mathematics Enthusiast, v. 10, n. 1, p. 245-278, 2013.

ONUCHIC, L. R; ALLEVATO, N. S. G. Pesquisa em Resolução de Problemas: caminhos, avanços e novas perspectivas. Bolema, Rio Claro (SP), v. 25, n. 41, p. 73-98, dez. 2011.

ONUCHIC, L. R. et al. (Orgs.). Resolução de Problemas: Teoria e Prática. Jundiaí: Paco Editorial, 2014.

PRADO, M. A.; ALLEVATO, N. S. G. O Ensino-Aprendizagem-Avaliação de Geometria através da Resolução de Problemas. Acta Scientiae, Canoas, v.12, n.01, p.24-42, jan./jun. 2010.

SELMER, S; KALE, U. Teaching mathematics through problem solving. Innovación Educativa, Toluca (Estado de México), vol. 13, n. 62, p.45-59, mai./ago. 2013.

SOUZA, L. B.; FOGLIE, F. T.; SANTOS, E. R. Função Exponencial através da Resolução de Problemas: relato de uma experiência no estágio supervisionado. Revista

Paranaense de Educação Matemática, Campo Mourão, v. 4, n. 7, p. 206-224, jul.-dez. 2015.

STEIN, M. K.; SMITH, M. S. Mathematical tasks as a framework for reflection: from research to practice Mathematics. Teaching in the Middle School, v. 3, n.4, p.268-275, jan. 1998. 
STEIN, M. K.; BOALER; J. SILVER, E. A. Teaching Mathematics through Problem Solving: Research Perspectives. In: SCHOEN, H. L. (Ed.). Teaching Mathematics through Problem Solving: Grades 6-12.Reston, VA: NCTM, 2003. p. 245-256.

STEIN, M. K. et al. Orchestrating productive mathematical discussions: Five practices for helping teachers move beyond show and tell. Mathematical Thinking and Learning, $v$. 10, n. 4, p. 313-340, 2008.

VAN DE WALLE, J. A. Matemática no Ensino Fundamental: formação de professores e aplicação em sala de aula. Porto Alegre: Artmed, 2009. 